\title{
A Study of WangFuzhi's Interpretation of the Book of Songs and His Poetics
}

\author{
Ahong Zhou, a, Zhen Yan ${ }^{1, b}$ \\ ${ }^{1}$ College of Literature and Journalism, Central South University, ChangSha 410012, China \\ azahcwp2016@163.com, ${ }^{\mathrm{b}}$ yuanliang160@163.com
}

\begin{abstract}
This paper studies the relationship between WangFuzhi's interpretation of the Book of Songs and his poetics. WangFuzhi did much study about the Book of Songs, spending more time and energy on the political and ethical enlightenment of this book than the literariness and artistry of it. According to his interpretation of the Book of Songs, which WangFuzhi considered as a Confucian classic rather than a literary writing, we can restore the historical condition of his poetics and can grasp the core of his poetics more accurately.
\end{abstract}

Keywords-WangFuzhi's poetics; The Book of Songs; Interpretation of the Book of Songs; Relationship

\section{INTRODUCTION}

Wang Fuzhi, born in 1619 and died in 1692, was a renowned philosopher, thinker and writer in ancient China. He lived in the late Ming and early Qing dynasties in which there are frequent wars. Wang Fuzhi was very patriotic. In his prime years, he wanted to work for the country in the Imperial court and on the battlefield. However, he failed both ways. In his later years, he lived a secluded life, devoting all his time and energy to reading, studying and writing. He wrote almost ten million words in his life, covering many aspects, including philosophy, history, literature, poetics and so on.

Wang Fuzhi's poetic thought is an important part of his overall academic thought, which is highly praised by the later generations. Mr. Xiao Chi puts Wang Fuzhi in the same position as Hegel [1], who had a great accomplishment in both philosophy and art, while Mr. YeLang thinks that "Wang Fuzhi and Ye Xie are Gemini constellations in the history of Chinese aesthetics."[2] Wang Fuzhi's poetic thought starts with the interpretation of the Book of Songs and is founded on the interpretation of the Book of Songs. At present, there are many researches on Wang Fuzhi's poetics, and there are a lot of concerns about Wang Fuzhi's interpretation of the Book of Songs. However, it is quite rare to combine Wang Fuzhi's interpretation of the Book of Songs with his poetic thoughts and study his poetics from the perspective of the interpretation of the Book of Songs. The relevant research has not been developed, and this is exactly what we're trying to do.
II. THE MAIN WRITINGS AND BASIC CONTENTS OF THE INTERPRETATION OF THE BOOK OF SONGS BY WANG FUZHI

In the face of numerous antique books, Wang Fuzhi paid great attention to the study of the Book of Songs. His writings about the research of the Book of Songs were quite fruitful.

\section{A. ShiJingBaiShu}

There were four volumes of books named ShiJingBaiShu, which interpreted the words and the names of the objects that appear in the Book of Songs. At the back of ShiJingBaiShu, there were two attachments named ShiJingKaoYi and ShiJingXieYunBian. The former studied the glyphs of the Book of Songs and the latter studied the phonology of this book.

It was said in the Concise directory of $\mathrm{Si} \mathrm{Ku}$ Quan Shu that "Wang Fuzhi's purpose of writing ShiJingBaiShu is to make up for the missing of Mao Shi Gu Xun Zhuan and Zheng Jian."'[3] Objectively speaking, this assessment is high and also relevant. Different from the general writings of words annotations in ancient China, in ShiJingBaiShu Wang Fuzhi combined the annotations of words with the meaning and the whole idea of the poem. In the way of explaining the meaning of a single word through the theme of the entire poem, thus not only the meaning of words is clear, but the purpose of the poem is also clear.

\section{B. ShiYi}

The book named ShiYi mainly interpreted the Book of Songs from the aspects of literature and aesthetics. In the book named the History of the study on the Book of Songs, Hong Zhanhou commented that Wang Fuzhi was the first person and ShiYi was the first writing to study the Book of Songs from a literary point of view during the three hundred years of the Qing Dynasty [4].

ShiYi in which there were only sixteen pieces had an important position in the history of Chinese ancient poetics and aesthetics. In this book, Wang Fuzhi put forward many important poetic propositions, such as the theory of XingGuanQunYuan, the theory of Yi and Qing-Jing theory. These theories were profound. Picked up the poetic theory of Yi for example. 
There were two seemingly opposite ideas in Wang Fuzhi's poetry, "commanded by Yi" (in pinyin "Ju Yi Yi Wei zhu") and "poetry's spirit not on Yi" (in pinyin "jubuzaiyi"). Scholars explained there were different connations of "Yi" in the two ideas. The former "yi" was considered to be related to imaginal thinking which is interlinked with emotion while the latter was an abstract concept. This paper points to the limitation of this explanation on the grounds that both of these two "Yi" refer to writers' intention and works' main idea. Although with the same "Yi", Wang Fuzhi's poetic theory offers a subtle blend of "commanded by Yi" (in pinyin "Ju Yi Yi Wei zhu") with "poetry's spirit not on Yi" (in pinyin "jubuzaiyi"). "Commanded by Yi" (in pinyin "Ju Yi Yi Wei zhu") is aimed at all styles including poetry while "poetry's spirit not on Yi" (in pinyin "jubuzaiyi") is limited to poetry. Poetry should obey the rule of "commanded by Yi" (in pinyin "Ju Yi Yi Wei zhu"), that is, writers' intentions and works' main idea determines how the poetry is. However, the spirit of poetry is not determined by "Yi", which means the spirit lies in the aesthetic image of an excellent combination generated by pratyaksa. The perfect fusion of the two ideas reflects Wang Fuzhi's profound grasp of stylistic features of poetry, which are emotional standard and imaginal thinking.

\section{ShiGuangZhuan}

In the book of ShiGuangZhuan, Wang Fuzhi studied the meaning of the Book of Songs, expressing his own opinions and theories on philosophy, politics, economy, literature, etc.

ShiGuangZhuan was an important book for studying Wang Fuzhi's poetry, which had not attracted enough attention in academia. Wang Fuzhi's main poetic thoughts and many of his poetic propositions come from this book. These poetic propositions, such as the relationship between poetry and the times, the function of poetry, the essence of poetry, the philosophy of poetry, were the most central and original propositions of Wang Fuzhi's poetry.

In addition, there were also some other explanations about the Book of Songs in Wang Fuzhi's other poetic writings. In his non-poetic works such as philosophy books and history books, there was a large number of quoting poetry. Through this behavior Wang Fuzhi actually expressed his understanding of the Book of Songs and the basic attitude of his poetry.

These writings formed Wang Fuzhi's interpretation of the Book of Songs. Wang Fuzhi's poetics is his whole theory of poetics while his interpretation of the Book of Songs is his study of the Book of Songs. Although they cannot be completely equivalent, there are overlaps and connections between them.

\section{THE DETERMINATION OF THE IDEOLOGICAL NATURE OF THE BOOK OF SONGS BY WANG FUZHI}

There is a common view in the scholarly world that Wang Fuzhi regarded the Book of Songs as a literary work. The main principal for this view is the text of Wang Fuzhi's ShiYi. However, in fact, Wang Fuzhi did not only understand the Book of Songs from the perspective of literature. More accurately speaking, the main perspective of Wang Fuzhi's study of the Book of Songs was not a literary one. From the length of the writings and the number of the words, we can easily draw a conclusion that Wang Fuzhi spent much more time and energy on ShiJingBaiShu and ShiGuangZhuan than on ShiYi, which was just an attachment to ShiJingBaiShu. And, as the SikuquanShu had said, it was a redundant attachment [5].

At the same time, ShiYi did not interpret the Book of Songs purely from the perspective of literature. In addition, when writing his philosophy, history and other books, Wang Fuzhi liked quoting many verses from the Book of Songs to prove his own point, which proved that Wang Fuzhi didn't take the Book of Songs as a purely literary writing. Furthermore, in some of his writings, Wang Fuzhi pointed out clearly that "the Book of Songs is the basis for political and ethical enlightenment". [6] All of these proved that Wang Fuzhi actually thought the Book of Songs as a Confucian classic.

To sum up, although Wang Fuzhi made a great contribution to the study of the Book of Songs from the perspective of literature and aesthetics, his starting point, ending point and focal point in the interpretation of the Book of Songs were still political and ethical enlightenment. His purpose of studying the Book of Songs is not to study the Book of Songs, but to do studying as a way of expressing the ideal of serving the country. He analyzed and summarized the root causes of the collapse of the Ming dynasty through the explanation of the classic such as the Book of Songs, profoundly pondered the reason of national decay from the cultural aspect, and also hoped to revive national confidence and restore the ideal social order also from the cultural aspect.

\section{THE INTERNAL RELATIONSHIP BETWEEN WANGFUZHI'S INTERPRETATION OF THE BOOK OF SONGS AND HIS POETICS}

Wang Fuzhi's interpretation of the Book of Songs and his poetics are closely related. From the perspective of interpretation of the Book of Songs, we can better master Wang Fuzhi's poetics.

First, we can restore the historical condition of Wang Fuzhi's poetics from studying his interpretation of the Book of Songs.

Hong Zhanhou said in the book named the History of the study on the Book of Songs that Wang Fuzhi's contribution to Chinese ancient poetics is not about how to annotate the Book of Songs, but to do art research of the Book of Songs, considering it as a literary writing. Wang Fuzhi was the first person to study the Book of Songs from a literary point of view during the three hundred years of the Qing Dynasty [7]. Many scholars had the same views as Mr. Hong. They think that it is commendable for Wang Fuzhi to talk about the Book of Songs 
from the literary level and treat the Book of Songs as a literary work. They think treating the Book of Songs as a literary work is more sensible and more reasonable than as a Confucian classic.

However, as mentioned above, Wang Fuzhi paid far more attention to the political and ethical enlightenment of the Book of Songs than the literariness and artistry of it. Factually, the starting point, end point and focus of Wang Fuzhi's interpretation of the Book of Songs were all of political and ethical enlightenment instead of the literariness and artistry. Moreover, in Wang Fuzhi's times, the visual angle of political and ethical enlightenment is not inferior to that of literature. This is Wang Fuzhi's historical condition which is also the historical condition we need to restore in studying Wang Fuzhi's poetics and his interpretation of the Book of Songs.

Second, we can grasp the core of Wang Fuzhi's poetics more accurately from studying his interpretation of the Book of Songs.

Above, we have restored the historical condition of Wang Fuzhi's acquaintance, which undoubtedly helps us to grasp the core of Wang Fuzhi's poetics and understand the relationship between his poetics and overall academic thoughts.

Wang Fuzhi identified himself as a Confucian scholar in his bones. Thus, the intention of his whole academic research, as well as his poetics, was a reflection of the reasons for the decline of the country from the cultural level. His hope is to restore the ideal social order and revitalize national confidence.

Nowadays, many researches only discuss many basic propositions of Wang Fuzhi's poetic thoughts from the angle of literature and aesthetics, resulting in cutting off the connection between his poetics and his whole academic thought. Therefore, it is difficult to grasp the essence and kernel of Wang Fuzhi's poetics.

Third, from the perspective of Wang Fuzhi's interpretation of the Book of Songs, the relationship between Wang Fuzhi's interpretation of the Book of Songs and his poetics can be fully studied.

The ancient Chinese poetics was largely constructed around and on the basis of the interpretation of the Book of Songs, and so was Wang Fuzhi's poetics. Wang Fuzhi's research on the Book of Songs not only summarized the concept of the predecessors, but also had his own unique creative ideas. His interpretation of the Book of Songs occupied an important position in both his own poetics and his whole academic ideas. It also played an important role in the interpretation of the Book of Songs and in the history of Chinese classical poetics.
The overall idea of Wang Fuzhi's poetics was established on the basis of the interpretation of the Book of Songs. The interpretation of the Book of Songs also laid the basic framework of Wang Fuzhi's poetic system. Many important propositions of Wang Fuzhi's poetics, such as the Qing theory, the theory of Xing Guan Qun Yuan, the theory of Yi, pratyaksa theory, the relationship between poetry and music, all came from the interpretation of the Book of Songs. In the poetry selection, in the review of poets and in the criticism of other styles, Wang Fuzhi also followed the principles established in the interpretation of the Book of Songs.

\section{CONCLUSIONS}

According to Wang Fuzhi's main writings and basic contents of the interpretation of the Book of Songs by Wang Fuzhi, we can draw a conclusion that Wang Fuzhi spent more time and energy on the political and ethical enlightenment of the Book of Songs than the literariness and artistry of it. Wang Fuzhi considered the Book of Songs as a Confucian classic than a literary writing. There were very close relations between Wang Fuzhi's interpretation of the Book of Songs and his poetics. From studying his interpretation of the Book of Songs, we can restore the historical condition and grasp the core of Wang Fuzhi's poetics.

\section{ACKNOWLEDGEMENT}

In this paper, the research was sponsored by National Social Science Foundation of China (no.14BZW009) and the Fundamental Research Funds for the Central University of Central South University (no.2017zzts033).

\section{REFERENCES}

[1] XiaoChi. Chinese Poetry Aesthetics [M]. BeiJing: Peking University Press, 1986. 63.

[2] YeLang. Outline of Chinese Aesthetic History [M]. ShangHai: Shanghai People's Publishing House, 1985. 452-453.

[3] The Concise directory of Si Ku Quan Shu, WangFuzhi. ChuanShan's Book (Volume III) [M]. ChangSha: Yuelu bookstore, 2011. 289.

[4] Hong Zhanhou. The History of the study on the Book of Songs [M]. BeiJing: Zhonghua Book Company, 2002. 560.

[5] The Head Summary of Si Ku Quan Shu, WangFuzhi. ChuanShan's Book (Volume III) [M]. ChangSha: Yuelu bookstore, 2011. 288.

[6] ShiGuangZhuan, WangFuzhi. ChuanShan's Book (Volume III) [M]. ChangSha: Yuelu bookstore, 2011. 300.

[7] Hong Zhanhou. The History of the study on the Book of Songs [M]. BeiJing: Zhonghua Book Company, 2002. 560. 